\title{
Microstructure Evolution and Corrosion Properties of Electrodeposited SnZn Coatings containing Graphene-Oxide
}

\author{
Rekha M Y ${ }^{1 *}$ and Chandan Srivastava ${ }^{2}$ \\ 1. Department of Materials Engineering, Indian Institute of Science, Bangalore, India. \\ 2. Department of Materials Engineering, Indian Institute of Science, Bangalore, India. \\ * Corresponding author: myrekha23@gmail.com
}

Graphene/Graphene-Oxide (GO) is being considered as a corrosion resistant coating material due to its impermeability and chemical inertness [1]. Incorporation of GO into metallic coatings has resulted in significant enhancement in corrosion resistance property of the composite coatings [2]. This enhancement is a synergistic effect of the impermeability of GO towards corrosive media and the microstructural alterations caused by the incorporation of GO into the metallic coatings. This work illustrates the role of GO in microstructural evolution of SnZn-GO composite coating and its corrosion resistance behaviour.

Graphene-Oxide (GO) was synthesized by the modified Hummer's method [3]. Pure SnZn coating and SnZn-GO composite coating were electrodeposited over mild steel substrate using a DC power source. Mild steel substrate and zinc plate were used as cathode and anode respectively. The plating bath for $\mathrm{SnZn}$ coating contained $20 \mathrm{~g} \mathrm{l}^{-1}$ of $\mathrm{SnSO}_{4}, 20 \mathrm{~g} \mathrm{l}^{-1}$ of $\mathrm{ZnSO}_{4} .7 \mathrm{H}_{2} \mathrm{O}, 140 \mathrm{~g} \mathrm{l}^{-1}$ of C$_{6} \mathrm{H}_{11} \mathrm{NaO}_{7}, 20 \mathrm{~g} \mathrm{l}^{-1}$ of C $2 \mathrm{H}_{3} \mathrm{NaO}_{2}$, $0.5 \mathrm{~g} \mathrm{l}^{-1}$ of SLS. For SnZn-GO composite coatings, $0.5 \mathrm{~g} \mathrm{l}^{-1}$ of $\mathrm{GO}$ was dispersed into the electrolyte solution that was used for plating SnZn. $\mathrm{pH}$ of the electrolyte was maintained at 4.5. The current density of $6.25 \mathrm{~mA} \mathrm{~cm}^{-2}$ was applied. Plating time was kept at $20 \mathrm{~min}$ and electrodeposition was carried out at room temperature.

As synthesized GO was characterized. In the obtained X-ray photoelectron spectroscopy (XPS) profile (Figure 1(a)) the C1s XPS spectrum was deconvoluted into three distinct peaks at C-C (284.2 eV), C-O $(286.1 \mathrm{eV})$ and $\mathrm{C}=\mathrm{O}(287.3 \mathrm{eV})$. This clearly indicated a considerable degree of oxidation of graphite into GO [4]. Analysis of the Z-height profile from atomic force microscope (AFM) images (Figure 1(b)) of GO samples revealed the average thickness of the as-synthesized GO as $3.94 \pm 0.4 \mathrm{~nm}$.

SEM image of the SnZn-GO composite coating in Figure 2(a) reveals its compact and crack free morphology. TEM bright field image of the SnZn-GO composite coating cross-section sample is shown in Figure 2(b). In Figure 2(b), two distinct regions can be observed: region on the top containing GO sheet and adjacent region containing $\mathrm{Sn}$ and $\mathrm{Zn}$ grains. Figure 3(a) shows the high magnification scanning transmission electron microscopy-high angle annular dark field (STEM-HAADF) image of the SnZn-GO composite coating cross-section sample. It shows the presence of ultra-fine clusters/particles over the GO sheets. EDS compositional map of Zn, Sn and C shown respectively in Figure 3(b), 3(c) and 3(d) revealed that the particles over the exposed GO sheet are only composed of $\mathrm{Zn}$. This observation revealed the role of GO in microstructural evolution. Addition of GO causes microstructural refinement due to initial formation of $\mathrm{Zn}$ clusters/particles over the GO followed by growth of $\mathrm{Sn}$ in the spaces between the $\mathrm{Zn}$ islands.

Electrochemical corrosion analysis was performed for $\mathrm{SnZn}$ and $\mathrm{SnZn-GO}$ composite coatings in $3.5 \mathrm{wt} \%$ $\mathrm{NaCl}$ solution at room temperature. The corrosion parameters: corrosion potential $\left(\mathrm{E}_{\text {corr }}\right)$ and corrosion current density ( $\left.\mathrm{i}_{\text {corr }}\right)$ for the coatings were obtained from the Tafel polarization curves which is provided 
in Figure 4. The Ecorr values are $-1.09 \mathrm{~V}$ and $-0.91 \mathrm{~V}$ and icorr values are $27.9 \mu \mathrm{A} \mathrm{cm}^{-2}$ and $11.9 \mu \mathrm{A} \mathrm{cm} \mathrm{cm}^{-2}$ respectively for SnZn and SnZn-GO composite coatings. For SnZn-GO composite coating, the shift of

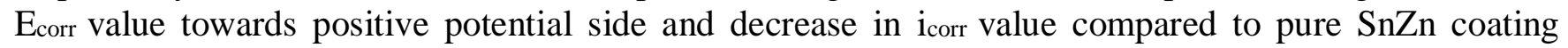
illustrates the SnZn-GO composite coating is nobler towards external aggressive media when compared to pure $S n Z n$ coating.

Fine scale distribution of $\mathrm{Zn}$ phase in GO-Sn matrix facilitated early and uniform formation of $\mathrm{ZnO}$, a corrosion product. The formation of protective oxide layer and impermeability of GO which hinders the penetration of electroactive media yielded better corrosion resistance property for the SnZn-GO composite coatings when compared to pure SnZn coating.

References:

[1] V Berry, Carbon 62 (2013), p. 1.

[2] MY Rekha, A Kamboj and C Srivastava, Thin Solid Films 653 (2018), p. 82.

[3] J Chen, B Yao, C Li and G Shi, Carbon 64 (2013), p. 225.

[4] DR Dreyer, S Park, CW Bielawski and RS Ruoff, Chemical Society Reviews 39 (2010), p. 228.

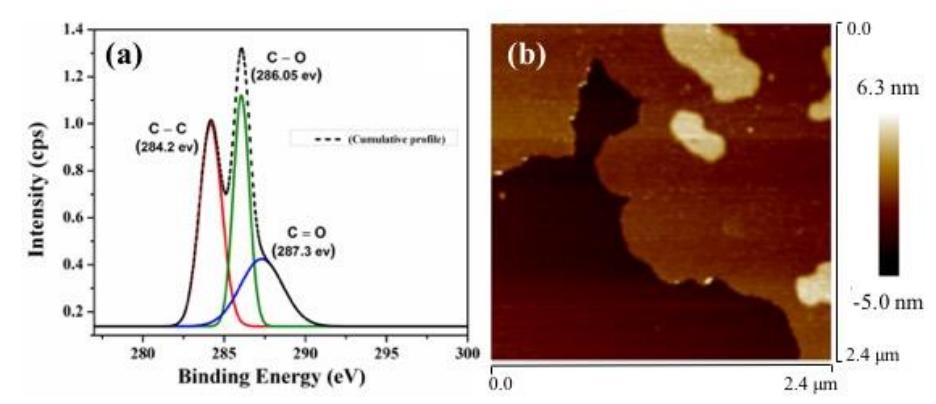

Figure 1. (a) Deconvoluted C1s XPS spectrum, (b) AFM topographical image and (c) TEM bright field image of as-synthesized graphene oxide.
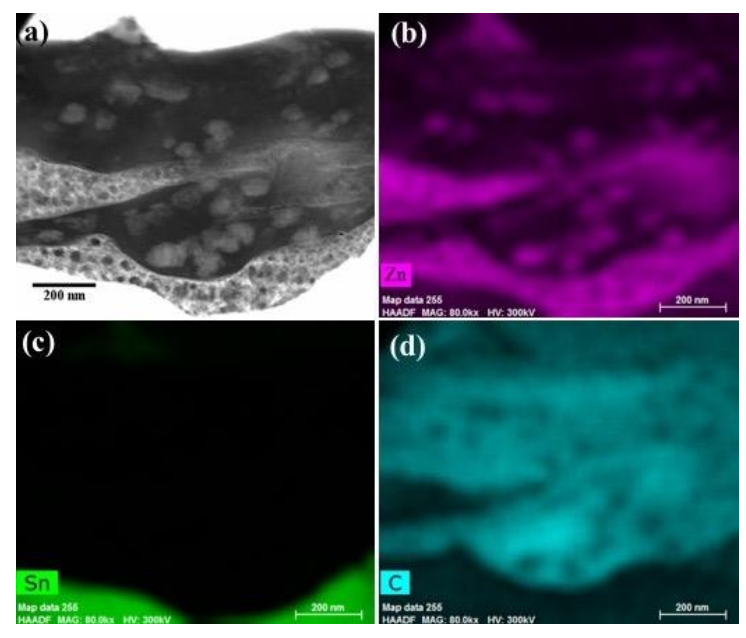

Figure 3. Representative (a) high-magnification STEM-HAADF image, EDS compositional map of (b) $\mathrm{Zn}$ region (c) Sn region and (d) $\mathrm{C}$ region of the crosssection sample obtained from SnZn-GO coating.

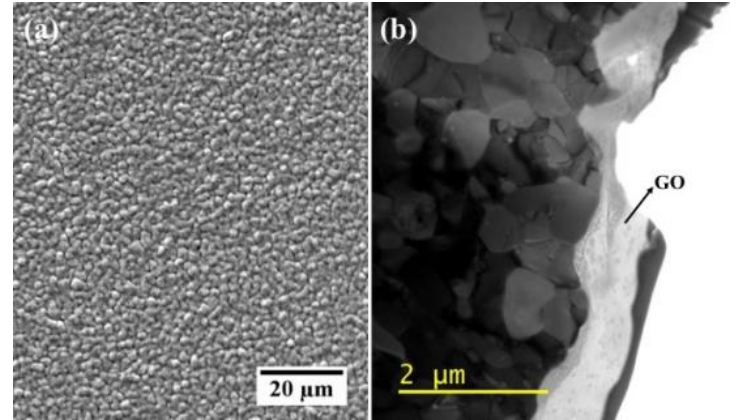

Figure 2. Representative low magnification (a) SEM image and (b) TEM bright field image of the cross-section sample obtained from SnZn-GO coating.

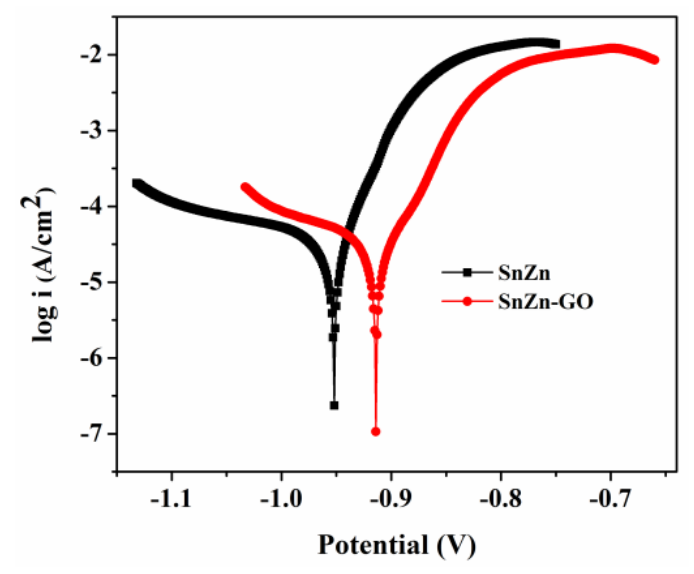

Figure 4. Tafel polarization curves for SnZn and SnZn-GO composite coating. 